\title{
Modelling Propelling Force in Swimming Using Numerical Simulations
}

\author{
Daniel A. Marinho1,2, Tiago M. Barbosa2,3, Vishveshwar R. Mantha',4, \\ Abel I. Rouboa ${ }^{2,5}$ and António J. Silva2,4 \\ ${ }^{1}$ University of Beira Interior, Department of Sport Sciences, Covilhã \\ ${ }^{2}$ Research Centre in Sports, Health and Human Development, Vila Real \\ ${ }^{3}$ Polytechnic Institute of Bragança, Department of Sport Sciences, Bragança \\ ${ }^{4}$ University of Trás-os-Montes and Alto Douro, Department of Sport Sciences, \\ Exercise and Health, Vila Real \\ ${ }^{5}$ University of Trás-os-Montes and Alto Douro, \\ Department of Engineering, Vila Real \\ Portugal
}

\section{Introduction}

In the sports field, numerical simulation techniques have been shown to provide useful information about performance and to play an important role as a complementary tool to physical experiments. Indeed, this methodology has produced significant improvements in equipment design and technique prescription in different sports (Kellar et al., 1999; Pallis et al., 2000; Dabnichki \& Avital, 2006). In swimming, this methodology has been applied in order to better understand swimming performance. Thus, the numerical techniques have been addressed to study the propulsive forces generated by the propelling segments (Rouboa et al., 2006; Marinho et al., 2009a) and the hydrodynamic drag forces resisting forward motion (Silva et al., 2008; Marinho et al., 2009b).

Although the swimmer's performance is dependent on both drag and propulsive forces, within this chapter the focus is only on the analysis of the propulsive forces. Hence, this chapter covers topics in swimming propelling force analysis from a numerical simulation technique perspective. This perspective means emphasis on the fluid mechanics and computational fluid dynamics methodology applied in swimming investigations. One of the main aims for performance (velocity) enhancement of swimming is to maximize propelling forces whilst not increasing drag forces resisting forward motion, for a given trust. This chapter will concentrate on numerical simulation results, considering the scientific simulation point-of-view, for this practical application in swimming.

Basically, numerical simulations consist of a mathematical model that replaces the NavierStokes equations with discretized algebraic expressions that can be solved by iterative computerized calculations. The Navier-Stokes equations describe the motion of viscous non-compressible fluid substances. These equations arise from applying Newton's second law to fluid motion, together with the assumption that the fluid stress is the sum of a diffusing viscous term (proportional to the gradient of velocity), plus a pressure term. A 
solution of the Navier-Stokes equations is called a velocity field or flow field, which is a description of the velocity of the fluid at a given point in space and time. Numerical simulations are based on the finite volume approach, where the equations are integrated over each control volume. It is required to discretize the spatial domain into small cells to form a volume mesh or grid, and then apply a suitable algorithm to solve the equations of motion (Marinho et al., 2010a). Additionally, several studies reported the importance of numerical simulations on testing and experimentation, reducing the total effort required in the experimental design and data acquisition (Lyttle \& Keys, 2006; Bixler et al., 2007). For instance, Lyttle and Keys (2006) referred that these numerical simulations can provide answers into many complex problems that have been unobtainable using physical testing techniques. One of its major benefits is the possibility to test many variations until one arrives at an optimal result, without physical/experimental testing.

Although some doubts on the accuracy of numerical simulations results, this numerical tool has been validated as being feasible in modelling complicated biological fluid dynamics, through a series of stepwise baseline benchmark tests and applications for realistic modelling of different scopes for hydro and aerodynamics of locomotion (Liu, 2002). Bixler et al. (2007) studied the accuracy of numerical analysis of the passive drag of a male swimmer. Comparisons of total drag force were performed between a real swimmer, a digital model of this same swimmer and a real mannequin based on the digital model. Bixler et al. (2007) found drag forces determined from the digital model using numerical simulations to be within $4 \%$ of the values assessed experimentally for the mannequin, although the mannequin drag was found to be $18 \%$ less than the real swimmer drag. In fact, this study has reinforced the idea of the validity and accuracy of numerical simulations in swimming research. Some differences were due to little body movements during the gliding position and to differences between the swimmer and the model since the swimmer's skin is flexible while the mannequin's skin is rigid. So, it is usually assumed that numerical simulations have ecological validity even for swimming research.

In the first part of the chapter, we introduce the issue, the main aims of the chapter and a brief explanation of the computational fluid dynamics methodology. Then, the contribution of different studies for swimming using numerical studies and some practical applications of this methodology are presented. During the chapter the authors will attempt to present the computational fluid dynamics data and to address some practical concerns to swimmers and coaches, comparing as well the numerical data with other experimental data available in the literature.

\section{Numerical simulation methodology}

\subsection{Mathematical formulation}

The flow around the swimmer seems to be turbulent (Sanders, 2001; Toussaint \& Truijens, 2005). Due to that reason Reynolds averaged Navier-Stokes equations with the Boussinesq hypothesis to model the Reynolds stresses are usually used (Hinze, 1975). The closure problem of the turbulent modeling is solved using k-epsilon model with appropriate wall functions. The system of equations for solving three-dimensional, incompressible fluid flow in steady-state regime is as follows:

$$
\operatorname{div} V=0
$$




$$
\begin{gathered}
\frac{\partial V}{\partial \mathrm{t}} \pm V \cdot \nabla V+\nabla p \pm \nabla\left(v+c_{\mu} \frac{k^{2}}{\varepsilon}\right)\left(\nabla V+\nabla V^{t}\right)=0 \\
\frac{\partial(\rho k)}{\partial \mathrm{t}}+\frac{\partial\left(\rho \mathrm{V}_{\mathrm{x}} k\right)}{\partial \mathrm{x}}+\frac{\partial\left(\rho \mathrm{V}_{\mathrm{y}} k\right)}{\partial \mathrm{y}}+\frac{\partial\left(\rho \mathrm{V}_{\mathrm{z}} k\right)}{\partial \mathrm{z}}=\frac{\partial\left(\frac{\mu_{\mathrm{t}}}{\sigma_{k}} \frac{\partial k}{\partial \mathrm{x}}\right)}{\partial \mathrm{x}}+\frac{\partial\left(\frac{\mu_{\mathrm{t}}}{\sigma_{k}} \frac{\partial k}{\partial \mathrm{y}}\right)}{\partial \mathrm{y}}+\frac{\partial\left(\frac{\mu_{\mathrm{t}}}{\sigma_{k}} \frac{\partial k}{\partial \mathrm{z}}\right)}{\partial \mathrm{z}}+\mu_{\mathrm{t}} \Phi-\rho \varepsilon \\
\frac{\partial(\rho k)}{\partial t}+\frac{\partial\left(\rho V_{x} \varepsilon\right)}{\partial x}+\frac{\partial\left(\rho V_{y} \varepsilon\right)}{\partial y}+\frac{\partial\left(\rho V_{z} \varepsilon\right)}{\partial z}=\frac{\partial\left(\frac{\mu_{t}}{\sigma_{\varepsilon}} \frac{\partial \varepsilon}{\partial x}\right)}{\partial x}+\frac{\partial\left(\frac{\mu_{t}}{\sigma_{\varepsilon}} \frac{\partial \varepsilon}{\partial y}\right)}{\partial y}+\frac{\partial\left(\frac{\mu_{t}}{\sigma_{\varepsilon}} \frac{\partial \varepsilon}{\partial z}\right)}{\partial z}+\mu_{t} \frac{\varepsilon}{k} \Phi-\mathrm{C}_{2} \frac{\rho \varepsilon^{2}}{k}
\end{gathered}
$$

Where $k$ is the turbulent kinetic energy and $\varepsilon$ is the turbulent kinetic energy dissipation ratio. $V_{x}, \mathrm{~V}_{\mathrm{y}}$ and $V_{z}$ represent the $\mathrm{x}, \mathrm{y}$ and $\mathrm{z}$ components of the velocity $V . \mu_{\mathrm{t}}$ is the turbulent viscosity and $\rho$ represents the fluid density. $v$ is the kinematic viscosity, $\Phi$ is the pressure strain, $C_{2}, C_{\mu}, \sigma_{\varepsilon}$ and $\sigma_{k}$ are model constants, 1.92, 0.09, 1.30 and 1.00, respectively.

The detailed terms of the k-epsilon model transport equations used during simulations are provided in user manual of Fluent documentation (Fluent, 2006).

\subsection{Digital model}

One of the main tasks to carryout numerical simulations is to define the digital model of the swimmer. The majority of the studies performed on this field used segments of the human body, representative of propelling segments, i.e., the hand and the forearm (Bixler \& Schloder, 1996; Rouboa et al., 2006).

In order to create the three-dimensional digital model computer tomography scans of a hand and forearm segments of an Olympic swimmer were applied. With these data we converted the values into a format that can be read in Gambit, Fluent ${ }^{\circledR}$ pre-processor. Fluent ${ }^{\circledR}$ software is used to simulate the fluid flow around structures, allowing the analysis of values of pressure and speed around (i.e. the hand and forearm of a swimmer). With these values we can calculate force components through integration of pressures on the hand/forearm surfaces, using a realistic model of these human segments.

Eighteen cross-sectional scans of the right arm (hand and forearm) were obtained using a Toshiba ${ }^{\circledR}$ Aquilion 4 computer tomography scanner. Computer tomography scans were obtained with configuration of V2.04 ER001. A $2 \mathrm{~mm}$ slice thickness with a space of $1 \mathrm{~mm}$ was used. The subject was an Olympic level swimmer, who participated in the 2004 Olympic Games in Athens. The subject was lying with his right arm extended upwards and fully pronated. The thumb was adducted and the wrist was in a neutral position (Marinho et al., 2010b). The appropriate ethical committee of the institution in which it was performed has approved this protocol, and the subject consented to participate in this work.

The transformation of values from the computer tomography scans into nodal coordinates in an appropriate coordinate system demands the use of image processing techniques. The image-processing program used in this study was the Anatomics Pro ${ }^{\circledR}$. This program allowed obtaining the boundaries of the human segments, creating a three-dimensional reconstruction of the swimmer hand and forearm.

At first, before processing and converting procedures the data was prepared, namely by observing the computer tomography data and erasing the non-relevant parts of the anatomical model. For example, surfaces supporting the subject were also scanned, reason 
why it had to be defined the relevant points and deleted the irrelevant ones. This step was also conducted using the software FreeForm Sensable ${ }^{\circledR}$. Finally, the data was converted into an IGES format (*.igs), that could be read by Gambit/Fluent ${ }^{\circledR}$ to define the finite volume approach through the three-dimensional surfaces (Marinho et al., 2010b).

\subsection{Simulations}

The dynamic fluid forces produced by the hand, lift (L) and drag (D), were measured in this study. These forces are functions of the fluid velocity and they were measured by the application of the equations 5 and 6 , respectively:

$$
\begin{aligned}
& D=C_{D}{ }^{\frac{1}{2}} \rho A v^{2} \\
& L=C_{L}^{\frac{1}{2}} \rho A v^{2}
\end{aligned}
$$

In equations 5 and $6, v$ is the fluid velocity, $C_{D}$ and $C_{L}$ are the drag and lift coefficients, respectively, $\rho$ is the fluid density and $A$ is the projection area of the model for different angles of attack used in this study.

The whole domain was meshed with a hybrid mesh composed of prisms and pyramids. Significant efforts were conducted to ensure that the model would provide accurate results by decreasing the grid node separation in areas of high velocity and pressure gradients.

Angles of attack of hand models of $0^{\circ}, 15^{\circ}, 30^{\circ}, 45^{\circ}, 60^{\circ}, 75^{\circ}$ and $90^{\circ}$, with a sweep back angle of $0^{\circ}$ (thumb as the leading edge) were used for the calculations (Schleihauf, 1979).

Steady-state analyses were performed using the Fluent ${ }^{\circledR}$ code and the drag and lift coefficients were calculated for a flow velocity of $2.0 \mathrm{~m} / \mathrm{s}$ (Lauder et al., 2001; Rouboa et al., 2006).

We used the segregated solver with the standard k-epsilon turbulence model because this turbulence model was shown to be accurate with measured values in a previous research (Moreira et al., 2006).

All numerical computational schemes were second-order, which provides a more accurate solution than first-order schemes. We used a turbulence intensity of $1.0 \%$ and a turbulence scale of $0.10 \mathrm{~m}$. The water temperature was $28^{\circ} \mathrm{C}$ with a density of $998.2 \mathrm{~kg} \cdot \mathrm{m}^{-3}$ and a viscosity of $0.001 \mathrm{~kg} / \mathrm{m} / \mathrm{s}$. Incompressible flow was assumed. The measured forces on the hand models were decomposed into drag $\left(C_{D}\right)$ and lift $\left(C_{L}\right)$ coefficients, using equations 5 and 6 .

\section{Propelling force}

\subsection{Definition}

Swimming is characterized by the intermittent application of a propulsive force (thrust) to overcome a velocity-dependent water resistance (hydrodynamic drag). The thrust is generated by a combination of arm, leg and body movements and lead to variations of thrust and velocity. Different fluctuations in thrust, drag and velocity among different techniques and different level of skills contribute to the highly variable performance in swimming. Swimming performance can be studied by analysing the interaction of propelling and resistive forces. In this sense, a swimmer will only enhance performance by minimizing resistive forces that act on the swimming body at a given velocity and/or by increasing the propulsive forces produced by the propelling segments. Furthermore, a third performance-enhancing factor would be to do this with a minimal enhancement of physiological or energetic costs (Barbosa et al., 2010). 
Effective propelling force can be defined as the component of the total propulsive force acting in the direction of moving. This force is produced due to the interaction of the swimmer with the water allowing overcoming hydrodynamic drag forces resisting forward motion. Thus, it is a hydrodynamic force with the same direction of the movement but opposite to drag force.

There are several mechanisms responsible to produce propelling forces, although some of them seemed to be more efficient than others. This fact seems to distinguish swimmers of different level, since some mechanisms allow producing the same work with less energy consumption (Barbosa et al., 2010). Knowing the most effective way to produce propulsive force should play a major role in swimming training.

\subsection{Relative contribution of drag and lift forces}

The relative contribution of drag and lift forces to overall propulsion is one of the most discussed issues in swimming hydrodynamics research.

Bixler and Riewald (2002) evaluated the steady flow around a swimmer's hand and forearm at various angles of attack and sweep back angles. The digital model was created based upon an adult male's right forearm and hand with the forearm fully pronated using similar procedures abovementioned. Force coefficients measured as a function of angle of attack showed that forearm drag was essentially constant and forearm lift was almost null. Additionally, hand drag presented the minimum value near angles of attack of $0^{\circ}$ and $180^{\circ}$ and the maximum value was obtained near $90^{\circ}$, when the model is nearly perpendicular to the flow. Hand lift was almost zero at $95^{\circ}$ and presented the highest values near $60^{\circ}$ and $150^{\circ}$. Regarding the water channel analysis, Schleihauf (1979) reported that lift coefficient values increased up to an attack angle around $40^{\circ}$ and then decreased, although some differences with respect to the sweepback angle were observed. Drag coefficient values increased with increasing the attack angle and were less sensitive to sweepback angle changes.

Silva et al. (2008), using a real digital model of a swimmer hand and forearm, confirmed the supremacy of the drag component. They also revealed an important contribution of lift force to the overall propulsive force production by the hand/forearm in swimming phases, when the angle of attack is close to $45^{\circ}$. The drag coefficient presented higher values than the lift coefficient for all angles of attack. In fact, the drag coefficient increased with the angle of attack showing the maximum values with an angle of attack of $90^{\circ}$ and the minimum values with an angle of attack of $0^{\circ}$. The lift coefficient of the model presented the maximum values with an angle of $45^{\circ}$. Silva et al. (2008) obtained values of lift coefficient very similar for the angles of attack of $0^{\circ}$ and $90^{\circ}$, although the minimum values were obtained with an angle of attack of $90^{\circ}$. Sato and Hino (2002) showed values of drag coefficient higher than lift coefficient at all angles of attack. From the results of the simulations the authors suggested that the resultant force was maximal with an angle of attack of $105^{\circ}$ and the direction of the resultant force in that situation was $-13^{\circ}$. Based on this analysis, the authors suggested stroke backward and with a little-finger-ward, out sweep motion, as the best stroke motion to produce the maximum thrust during underwater path.

Another interesting numerical report, when the sweep back angle is considered, was that more lift force is generated when the little finger leads the motion than when the thumb leads (Bixler \& Riewald, 2002; Silva et al. 2008).

\subsection{Contribution of arms and legs to propulsion}

Another important issue is related to the contribution of arms and legs to propulsion. It is almost consensual that most propulsion is generated by the arms' actions. In front crawl 
swimming, it was found (Hollander et al., 1988; Deschodt, 1999) that about 85 to $90 \%$ of propulsion is produced by the arms' movements. Accordingly, the majority of the research under this scope is performed on arm's movements. Nevertheless, leg's propulsion should not be disregarded and future studies under this field should be addressed, helping swimmers to enhance performance. In this section it seems pertinent to present some interesting and pioneer studies of Lyttle and Keys (2006). These authors performed a three-dimensional numerical analysis, modelling the swimmer performing two kinds of underwater dolphin kick used after starts and turns, after the swimmer push-off from the wall: (i) high amplitude and low frequency dolphin kick and; (ii) low amplitude and high frequency dolphin kick. Main data demonstrated an advantage of using the large slow kick, over the small fast kick, concerning the velocity range that underwater dolphin kicks are used. In addition, changes were also made into the input kinematics (ankle plantar flexion angle) to demonstrate the practical applicability of the model. While the swimmer was gliding at $2.18 \mathrm{~m} / \mathrm{s}$, a $10^{\circ}$ increase in ankle plantar flexion created greater propulsive force during the kick cycle. These results demonstrated that increasing angle flexibility would increase the stroke efficiency for the subject that was modelled, although some caution should be made when transferring this data into other swimmers with different anthropometrical profile.

Regarding arms' propulsion, Lecrivain et al. (2008) reported that the arm (and not only the hand and forearm) provided effective propulsion through most of the stroke, and this must be considered when studying the arm propulsion. In fact, Gardano and Dabnichki (2006) underlined the importance of the analysis of the entire arm rather than different parts of it. Thus, the authors concluded that drag profiles differed substantially with the elbow flexion angle, as the maximum value could vary by as much as $40 \%$. In addition, Gardano and Dabnichki (2006) stated that maximum drag force was achieved by $160^{\circ}$ of elbow angle. A prolonged plateau between $50^{\circ}$ and $140^{\circ}$ indicated greater momentum generated at $160^{\circ}$ in comparison with the other configurations. This fact suggests a strong possibility for the existence of an optimal elbow angle for the generation of a maximum propulsive force. However, these findings are only possible to confirm if an entire model of the swimmer's arm, its movement relative to the body and the body's movement relative to the water are computed (Marinho et al., 2009c). This concern seems also an interesting topic to address in further studies.

\subsection{Fingers relative position}

Regarding arms' actions, a large inter-subject range of fingers relative position can be observed during training and competition, regarding thumb position and finger spreading. Due to the inherent inefficiency of human swimming, the question is: do any of these strategies enhance performance or is it just a more comfortable hand posture that swimmers assumed?

Regarding thumb position, although some differences in the results of different studies (Schleihauf, 1979; Takagi et al., 2001; Marinho et al., 2009a), main data seemed to indicate that when the thumb leads the motion (sweep back angle of $0^{\circ}$ ) a hand position with the thumb abducted would be preferable to an adducted thumb position. Additionally, Marinho et al. (2009a) found, for a sweep back angle of $0^{\circ}$, that the position with the thumb abducted presented higher values than the positions with the thumb partially abducted and adducted at angles of attack of $0^{\circ}$ and $45^{\circ}$. At an angle of attack of $90^{\circ}$, the position with the thumb adducted presented the highest value of resultant force. Schleihauf (1979), using experimental procedures, found that the position with the thumb fully abducted showed a maximum lift coefficient at an angle of attack of $15^{\circ}$, whereas the models with partial thumb abduction 
showed a maximum value of lift coefficient at higher angles of attack $\left(45^{\circ}-60^{\circ}\right)$. In these orientations, the position with the thumb partially abducted presented higher values than with the thumb fully abducted. Moreover, Takagi et al. (2001) also applying experimental measurements revealed that the thumb position influenced the lift force. For a sweep back angle of $0^{\circ}$ (as used in the study of Marinho et al., 2009a) the model with abducted thumb presented higher values of lift force, whereas for a sweep back angle of $180^{\circ}$ (the little finger as the leading edge), the adducted thumb model presented higher values of lift force. In addition, the drag coefficient presented similar values in the two thumb positions for a sweep back angle of $0^{\circ}$ and higher values in the thumb adducted position for a sweep back angle of $180^{\circ}$.

Regarding different finger spreading, Marinho et al. (2010c), using a numerical analysis, studied the hand with: (i) fingers close together, (ii) fingers with little distance spread (a mean intra finger distance of $0.32 \mathrm{~cm}$, tip to tip), and (iii) fingers with large distance spread $(0.64 \mathrm{~cm}$, tip to tip), following the same procedure when Schleihauf (1979) conducted his experimental research. Marinho et al. (2010c) found that for attack angles higher than $30^{\circ}$, the model with little distance between fingers presented higher values of drag coefficient when compared with the models with fingers closed and with large finger spread. For attack angles of $0^{\circ}, 15^{\circ}$ and $30^{\circ}$, the values of drag coefficient were very similar in the three models of the swimmer's hand. Moreover, the lift coefficient seemed to be independent of the finger spreading, presenting little differences between the three models. Nevertheless, Marinho et al. (2010c) were able to note slightly lower values of lift coefficient for the position with larger distance between fingers. In the same line of research, Minetti et al. (2009) showed, through numerical simulation of a three-dimensional model of the hand, that an optimal finger spacing $\left(12^{\circ}\right.$, roughly corresponding to the resting hand posture) increases the drag coefficient $(+8.8 \%)$, which is 'functionally equivalent' to a greater hand palm area, thus a lower stroke frequency can produce the same thrust, with benefits to muscle, hydraulic and propulsive efficiencies. These results suggested that the hand seems to create more propulsive force when fingers are slightly spread. Flow visualization, through numerical simulations, provides an explanation for the increased force associated with the optimum finger spacing.

\subsection{Steady vs. unsteady flow conditions}

The majority of the abovementioned studies were conducted only under steady state flow conditions. However, one knows (Schleihauf, 1979) that swimmers do not move their arms/hands under constant velocity and direction motions. Therefore, some authors (Sanders, 1999; Bixler \& Riewald, 2002; Sato \& Hino, 2002; Rouboa et al., 2006) referred that it is important to consider unsteady effects when swimming propulsion is analysed. For instance, Bixler and Schloder (1996) analysed the flow around a disc with a similar area of a swimmer hand. Different simulations with different initial velocity and acceleration were conducted to model identical real swimming conditions, especially during insweep and upsweep phases of the front crawl stroke. According to the obtained results the authors reported that the hand acceleration could increase the propulsive force by around $24 \%$ compared with the steady flow condition. Sato and Hino (2002) using also numerical and experimental data showed that the hydrodynamic forces acting on the accelerating hand was much higher than with a steady flow situation and these forces amplifies as acceleration increases. Rouboa et al. (2006) analysed the effect of swimmer's hand/forearm acceleration on propulsive forces generation using numerical simulation techniques. The main data underlined that under the hand/forearm acceleration condition, the measured values for propulsive forces were approximately $22.5 \%$ higher than the forces produced under the steady flow condition. Thus, these data suggests that drag and lift forces produced by the 
swimmers' hand in a determined time are dependent not only on the surface area, the shape and the velocity of the segment but also on the acceleration of the propulsive segment.

\subsection{Equipment}

Research in this scope is very scarce and when applied the main focus is related to analyse how can different equipment improve swimming performance due to a decrease in hydrodynamic drag (Neiva et al., 2011). The study of the effects of using different swimsuits is a good example (Roberts et al., 2003; Pendergast et al., 2006), emphasising the importance of compression effects due to swimsuits on drag reduction (Neiva et al., 2011). However, to the best of our knowledge, the effects on improving propelling force had lower attention by swimming scientific community. Some equipment used by swimmers, especially during training, can be tested using numerical simulation techniques, allowing understand the specific effects on propelling force. For instance, the effects of wearing fins, and different types of fins (Tamura et al., 2002), paddles, and other devices using during training should be tested attempting to elucidate coaches to improve training efficiency.

\section{Future research in swimming using numerical simulations}

Throughout this chapter, several future ideas have been presented to improve the application of numerical simulations in swimming research. One of our major aims is to be able to evaluate biomechanical situations that can be used by coaches and swimmers to swim faster and, thus to enhance performance. Therefore, the effective evaluation of true swimming conditions should be a main focus. Under this scope, main concerns should be addressed to analyse unsteady flow conditions, studying arms and legs propulsion during actual swimming, adding body roll, movement of the body, rotations and accelerations of the propelling segments, on different swimming techniques.

As mentioned above, the analysis of the effects of different equipment and facilities on propelling forces seems to be an interesting and an important issue to be dealt in future studies.

\section{Conclusion}

During this chapter, the authors attempted to present some important studies that have been conducted in swimming research using numerical simulations. Although there are some limitations of these studies, it seems that this numerical tool should not be disregarded. Numerical simulations can be used to evaluate several hydrodynamic issues, hence helping swimmers moving faster. In the current work some issues regarding the effect of propelling force on swimming performance were discussed. The authors are aware of some limitations, although they believe that they were able to show the practical applications of numerical simulations to swimmers and their coaches.

Moreover, it was an attempt to address some concerns to be improved in future investigations.

\section{Acknowledgement}

This work was supported by the Portuguese Government by Grants of the Science and Technology Foundation (PTDC/DES/098532/2008). 


\section{References}

Barbosa, T.M.; Bragada, J.A.; Reis, V.M.; Marinho, D.A.; Carvalho, C. \& Silva, J.A. (2010). Energetics and biomechanics as determining factors of swimming performance: updating the state of the art. Journal of Science and Medicine in Sports, 13, 262-269

Bixler, B. \& Schloder, M. (1996). Computational fluid dynamics: an analytical tool for the 21st century swimming scientist. Journal of Swimming Research, 11, 4-22.

Bixler, B.S. \& Riewald, S. (2002). Analysis of swimmer's hand and arm in steady flow conditions using computational fluid dynamics. Journal of Biomechanics, 35, 713-717.

Bixler, B.; Pease, D. \& Fairhurst, F. (2007). The accuracy of computational fluid dynamics analysis of the passive drag of a male swimmer. Sports Biomechanics, 6, 81-98.

Dabnichki, P. \& Avital, E. (2006). Influence of the position of crew members on aerodynamics performance of two-man bobsleigh. Journal of Biomechanics, 39, 2733-2742.

Deschodt, V. (1999). Relative contribution of arms and legs in human to propulsion in $25 \mathrm{~m}$ sprint front crawl swimming. European Journal of Applied Physiology, 80, 192-199.

Fluent (2006). Fluent 6.3 Documentation. Fluent Inc., Hanover.

Gardano, P. \& Dabnichki, P. (2006). On hydrodynamics of drag and lift of the human arm. Journal of Biomechanics, 39, 2767-2773.

Hinze, J.O. (1975). Turbulence. McGraw-Hill Publishing Co., New York.

Hollander, A.P.; de Groot, G.; van Ingen Schenau, G.; Kahman, R. \& Toussaint, H. (1988). Contribution of the legs to propulsion in Front Crawl swimming. In: Swimming Science V, B. Ungerechts, K. Wilke \& K. Reischle, (Eds.), 39-43, Human Kinetics Books, Illinois.

Kellar, W.P.; Pearse, S.R.G. \& Savill, A.M. (1999). Formula 1 car wheel aerodynamics. Sports Engineering, 2, 203-212.

Lauder, M.; Dabnichki, P. \& Bartlett, R. (2001). Improved accuracy and reliability of sweepback angle, pitch angle and hand velocity calculations in swimming. Journal of Biomechanics, 34, 31-39.

Lecrivain, G.; Slaouti, A.; Payton, C. \& Kennedy, I. (2008). Using reverse engineering and computational fluid dynamics to investigate a lower arm amputee swimmer's performance. Journal of Biomechanics, 41, 2855-2859.

Liu, H. (2002). Computational biological fluid dynamics: digitizing and visualizing animal swimming and flying. Integrative and Comparative Biology, 42, 1050-1059.

Lyttle, A. \& Keys, M. (2006). The application of computational fluid dynamics for technique prescription in underwater kicking. Portuguese Journal of Sport Sciences, 6, Suppl. 2, 233-235.

Marinho, D.A.; Rouboa, A.I.; Alves, F.B.; Vilas-Boas, J.P.; Machado, L.; Reis, V.M. \& Silva, A.J. (2009a). Hydrodynamic analysis of different thumb positions in swimming. Journal of Sports Science and Medicine, 8, 1, 58-66.

Marinho, D.A.; Reis, V.M.; Alves, F.B.; Vilas-Boas, J.P.; Machado, L.; Silva, A.J. \& Rouboa, A.I. (2009b). The hydrodynamic drag during gliding in swimming. Journal of Applied Biomechanics, 25, 3, 253-257.

Marinho, D.A.; Barbosa, T.M.; Kjendlie, P.L.; Vilas-Boas, J.P.; Alves, F.B.; Rouboa, A.I. \& Silva, A.J. (2009c). Swimming simulation: a new tool for swimming research and practical applications. In: Lecture Notes in Computational Science and Engineering CFD for Sport Simulation, M. Peters (Ed.), 33-62. Springer, Berlin.

Marinho, D.A.; Barbosa, T.M.; Kjendlie, P.L.; Mantripragada, N.; Vilas-Boas, J.P.; Machado, L.; Alves, F.B.; Rouboa, A.I. \& Silva, A.J. (2010a). Modeling hydrodynamic drag in 
swimming using computacional fluid dynamics, In: Computational Fluid Dynamics, H.W. Oh (Ed.), 391-404. INTECH Education and Publishing, Vienna.

Marinho, D.A.; Reis, V.M.; Vilas-Boas, J.P.; Alves, F.B.; Machado, L.; Rouboa, A.I. \& Silva, A.J. (2010b). Design of a three-dimensional hand/forearm model to apply Computational Fluid Dynamics. Brazilian Archives of Biology and Technology, 5(2), 437-442.

Marinho, D.A.; Barbosa, T.M.; Reis, V.M.; Kjendlie, P.L.; Alves, F.B.; Vilas-Boas, J.P.; Machado, L.; Silva, A.J. \& Rouboa, A.I. (2010c). Swimming propulsion forces are enhanced by a small finger spread. Journal of Applied Biomechanics, 26, 87-92.

Minetti, A.E.; Machtsiras, G. \& Masters, J.C. (2009). The optimum finger spacing in human swimming. Journal of Biomechanics, 42, 13, 2188-2190

Moreira, A.; Rouboa, A.; Silva, A.; Sousa, L.; Marinho, D.; Alves, F.; Reis, V.; Vilas-Boas, J.P.; Carneiro, A. \& Machado, L. (2006). Computational analysis of the turbulent flow around a cylinder. Portuguese Journal of Sport Sciences, 6(Suppl. 1), 105.

Neiva, H.P.; Vilas-Boas, J.P.; Barbosa, T.M.; Silva, A.J. \& Marinho, D.A. (2011). 13th FINA World Championships: Analysis of Swimsuits Used By Elite Male Swimmers. Journal of Human Sport and Exercise, 6, 1, 87-93.

Pallis, J.M.; Banks, D.W. \& Okamoto, K.K. (2000). 3D computational fluid dynamics in competitive sail, yatch and windsurfer design, In: The Engineering of Sport: Research, Development and Innovation, F. Subic \& M. Haake (Eds.), 75-79. Blackwell Science, Oxford.

Pendergast, D.R.; Capelli, C.; Craig Jr, A.B.; di Prampero, P.E.; Minetti, A.E.; Mollendorf1, J.; Termin, A. \& Zamparo, P. (2006). Biophysics in swimming. Portuguese Journal of Sport Sciences, 6, Suppl. 2, 185-189.

Roberts, B.S.; Kamel, K.S.; Hedrick, C.E.; MLean, S.P. \& Sharpe, R.L. (2003). Effect of Fastskin suit on submaximal freestyle swimming. Medicine and Science in Sports and Exercise, 35, 519-524.

Rouboa, A.; Silva, A.; Leal, L.; Rocha, J. \& Alves, F. (2006). The effect of swimmer's hand/forearm acceleration on propulsive forces generation using computational fluid dynamics. Journal of Biomechanics, 39, 1239-1248.

Sanders, R.H. (1999). Hydrodynamic characteristics of a swimmer's hand. Journal of Applied Biomechanics, 15, 3-26.

Sanders, R.B.; Rushall, H., Toussaint, H., Steager, J. \& Takagi, H. (2001). Bodysuit yourself but first think about it. American Swimming Magazine, 5, 23-32.

Sato, Y \& Hino, T. (2002). Estimation of thrust of swimmer's hand using CFD. In: Proceedings of 8th symposium on nonlinear and free-surface flows, 71-75. Hiroshima.

Schleihauf, R.E. (1979). A hydrodynamic analysis of swimming propulsion. In: Swimming III, J. Terauds \& E.W. Bedingfield (Eds.), 70-109. University Park Press, Baltimore.

Silva, A.J.; Rouboa, A.; Moreira, A.; Reis, V.; Alves, F.; Vilas-Boas, J.P. \& Marinho, D. (2008). Analysis of drafting effects in swimming using computational fluid dynamics. Journal of Sports Science and Medicine, 7, 1, 60-66.

Takagi, H.; Shimizu, Y.; Kurashima, A. \& Sanders, R. (2001). Effect of thumb abduction and adduction on hydrodynamic characteristics of a model of the human hand. In: Proceedings of Swim Sessions of the XIX International Symposium on Biomechanics in Sport, J. Blackwell \& R. Sanders (Eds.), 122-126. University of San Francisco, San Francisco.

Tamura, H.; Nakazawa, Y.; Sugiyama, Y.; Nomura, T. \& Torii, N. (2002). Motion analysis and shape evaluation of a swimming monofin. The Engineering Sports, 4, 716-724.

Toussaint, H. \& Truijens, M. (2005). Biomechanical aspects of peak performance in human swimming. Animal Biology, 55, 1, 17-40. 


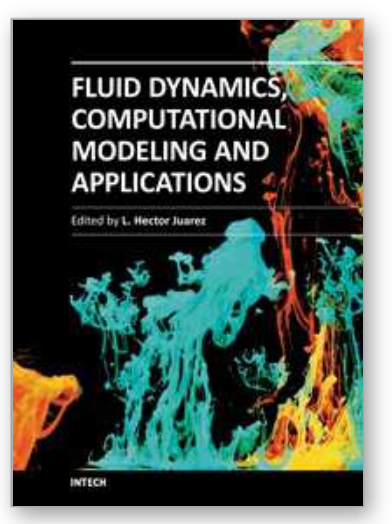

\author{
Fluid Dynamics, Computational Modeling and Applications \\ Edited by Dr. L. Hector Juarez
}

ISBN 978-953-51-0052-2

Hard cover, 660 pages

Publisher InTech

Published online 24, February, 2012

Published in print edition February, 2012

The content of this book covers several up-to-date topics in fluid dynamics, computational modeling and its applications, and it is intended to serve as a general reference for scientists, engineers, and graduate students. The book is comprised of 30 chapters divided into 5 parts, which include: winds, building and risk prevention; multiphase flow, structures and gases; heat transfer, combustion and energy; medical and biomechanical applications; and other important themes. This book also provides a comprehensive overview of computational fluid dynamics and applications, without excluding experimental and theoretical aspects.

\title{
How to reference
}

In order to correctly reference this scholarly work, feel free to copy and paste the following:

Daniel A. Marinho, Tiago M. Barbosa, Vishveshwar R. Mantha, Abel I. Rouboa and António J. Silva (2012). Modelling Propelling Force in Swimming Using Numerical Simulations, Fluid Dynamics, Computational Modeling and Applications, Dr. L. Hector Juarez (Ed.), ISBN: 978-953-51-0052-2, InTech, Available from: http://www.intechopen.com/books/fluid-dynamics-computational-modeling-and-applications/modellingpropelling-force-in-swimming-using-numerical-simulations

\section{INTECH}

open science | open minds

\section{InTech Europe}

University Campus STeP Ri

Slavka Krautzeka 83/A

51000 Rijeka, Croatia

Phone: +385 (51) 770447

Fax: +385 (51) 686166

www.intechopen.com

\section{InTech China}

Unit 405, Office Block, Hotel Equatorial Shanghai

No.65, Yan An Road (West), Shanghai, 200040, China 中国上海市延安西路65号上海国际贵都大饭店办公楼 405 单元

Phone: $+86-21-62489820$

Fax: $+86-21-62489821$ 
(C) 2012 The Author(s). Licensee IntechOpen. This is an open access article distributed under the terms of the Creative Commons Attribution 3.0 License, which permits unrestricted use, distribution, and reproduction in any medium, provided the original work is properly cited. 